\title{
INTERNAL IMPEDANCE OF THE LITHIUM-ION SECONDARY CELLS USED FOR REIMEI SATELLITE AFTER THE ELEVEN YEARS OPERATION IN SPACE
}

\author{
Yoshitsugu Sone ${ }^{(1,2)}$, Hiromi Watanabe ${ }^{(3)}$, Kohei Tanaka ${ }^{(2)}$, Omar Samuel Mendoza-Hernandez ${ }^{(1)}$, \\ Seisuke Fukuda ${ }^{(1,2)}$, Masayuki Itagaki ${ }^{(4)}$, Keita Ogawa ${ }^{(5)}$, Kazushi Asamura ${ }^{(1,2)}$, Atsushi Yamazaki ${ }^{(1)}$, \\ Hiroyuki Nagamatsu $^{(1)}$, Yosuke Fukushima ${ }^{(1,2)}$, Hirofumi Saito ${ }^{(1,3)}$ \\ (1) Japan Aerospace Exploration Agency, 3-1-1 Yoshinodai Chuo, Sagamihara, Kanagawa, 252-5210 Japan, \\ Email:sone.yoshitsugu@jaxa.jp \\ (2) The Graduate University of Advanced Studies (SOKENDAI), 3-1-1 Yoshinodai, Chuo, Sagamihara, Kanagawa, \\ 252-5210 Japan, Email:fukuda.seisuke@jaxa.jp \\ (3) The University of Tokyo, Saito Lab., 3-1-1 Yoshinodai Chuo-ku, Sagamihara, Kanagawa, 252-5210 Japan, \\ Email:saito.hirofumi@jaxa.jp \\ (4) Tokyo University of Science, 2641 Yamazaki, Noda, Chiba, 278-8510Japan, Email:itagaki@rs.noda.tus.ac.jp \\ (5) Advanced Engineering Services Co. Ltd., Mitsui Building 7F, 1-6-1, Takezono, Tsukuba, Ibaraki, 305-0032 Japan, \\ Email:k_ogawa@aes.co.jp
}

\begin{abstract}
The lithium-ion secondary batteries have been widely used for the space programs, today. Among them, REIMEI was one of the first satellites using lithium-ion secondary battery. In 2005, the satellite was launched, and injected into the low earth polar orbit. Eleven years has passed since the launch and over 60,000 cycles of charge and discharge was experienced in space.

The lithium-ion secondary cell of the REIMEI battery was designed using spinel manganese oxide type material for the positive electrode, and the graphitized type carbon for the negative electrode. The cell case was made of aluminium laminated film and the structure was reinforced by the epoxy resin and aluminium housing. After the operation of eleven years, the cells still maintain the appropriate uniform balance and operative. In order to identify the internal condition of the battery/cell, we calculated the ac impedance by the pulse duration to the on-board battery.
\end{abstract}

\section{INTRODUCTION}

Today, lithium-ion secondary battery is widely used for the spacecraft and satellites. When the lithium-ion secondary cells started to be used for the space programs, 'off-the-shelf' lithium-ion secondary cells received much attention. The European piggy-back satellite 'PROBA' uses lithium-ion batteries produced by AEA using lithium-ion secondary cells from SONY. The same technology was also applied to European planetary missions such as the satellite 'ROSETTA' and the 'MARS-EXPRESS' [1].

The Japanese satellite 'REIMEI' was also one of the examples where the off-the-shelf lithium-ion secondary cells were used [2-6]. The satellite was an engineering demonstrator for the advanced space technologies. [2, 3] Initially it also had a scientific mission to observe aurora around the polar region using three cameras with different filters for the wave length of the light. The

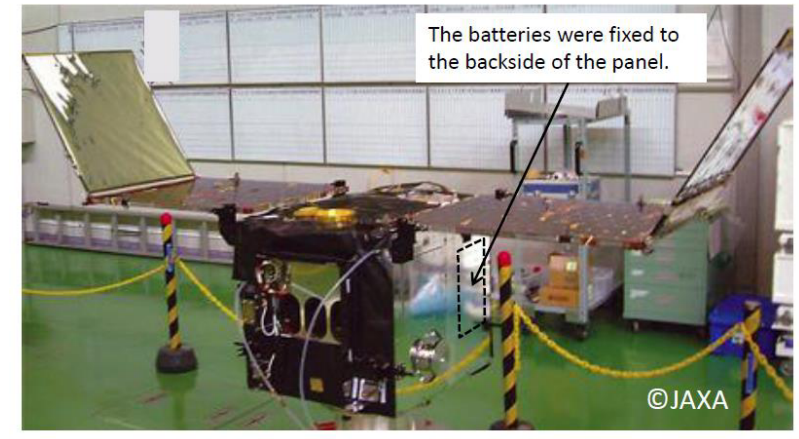

Figure 1. Photograph of the 'REIMEI' satellite (Code name before the launch was INDEX) nderdevelopment.

science mission was terminated in eight years after the launch. Today, the satellite is still maintained to observe the degradation mechanisms of the battery in space.

Recently, the 'passivation' of the satellite in the end-oflife was focused [7, 8], and the estimation of the health condition like impedance [9] of the batteries/cells in space was also discussed.

In this paper, we discuss the ac and dc impedance conditions of the batteries/cells after the long term operation of REIMEI satellite in space.

Table 1. The outline of the satellite 'REIMEI'.

\begin{tabular}{|l|l|}
\hline Designation Code & 2005-031B \\
\hline Launch Date & $06: 10$, August 24, 2005 (JST) \\
\hline Location & Baikonur Cosmodrome \\
\hline Size & $60 \mathrm{~cm} \mathrm{x} 60 \mathrm{~cm} \mathrm{x} \mathrm{70} \mathrm{cm}$ \\
\hline Mass & $60 \mathrm{~kg}$ \\
\hline Orbiter & Quasi-circular orbit \\
\hline Altitude & $610-654 \mathrm{~km}$ \\
\hline Inclination & 97.8 degrees \\
\hline Period & 97 minutes \\
\hline Attitude control & Three-axis stabilization \\
\hline
\end{tabular}


Table 2 The specifications of the lithium-ion secondary cell for REIMEI battery.

\begin{tabular}{|l|l|}
\hline Electrode & $\begin{array}{l}\text { Spinel } \mathrm{LiMn}_{2} \mathrm{O}_{4} \text { (positive), } \\
\text { Graphite type carbon (negative) }\end{array}$ \\
\hline Name plate capacity & $3 \mathrm{Ah}$ \\
\hline Mass & $75 \mathrm{~g}$ \\
\hline Volume & $145 \mathrm{~mm} \times 80 \mathrm{~mm} \times 4 \mathrm{~mm}$ \\
\hline Energy density & $158 \mathrm{Wh} / \mathrm{kg}, 340 \mathrm{Wh} / \mathrm{L}$ \\
\hline Charge voltage & $4.1 \mathrm{~V}$ (nominal), \\
& $4.2 \mathrm{~V}$ (temporal) \\
\hline Discharge limitation & $3.0 \mathrm{~V}$ \\
\hline
\end{tabular}

\section{OUTLINE OF REIMEI AND CELL/BATTERY}

'REIMEI' satellite before launch is shown Fig. 1. The satellite was launched in August, 2015 [2, 3]. It was an engineering demonstrator for the cutting-edge satellite technology. It also carried onboard instruments for scientific aurora observations which were suitable for a small satellite. The outline of the satellite is shown in Tab. 1.

For the main bus battery, the off-the-shelf type lithiumion secondary cells were used for the REIMEI battery [4, 5]. The specifications of the cell are listed in Tab. 2. It was a lithium-ion secondary cell, whose positive material was spinel manganese oxide and the negative was graphitized carbon. The upper limitation for the charge voltage was $4.2 \mathrm{~V} / \mathrm{cell}$. We decided that the nominal charge voltage should be up to $4.1 \mathrm{~V} /$ cell to realize the longer operational period of the satellite.

For a battery, seven cells were connected in series in order to realize the $28 \mathrm{~V}$-class-bus-voltage. Two batteries were connected in parallel and installed into the aluminium case. The cell case was aluminium laminated file, and the cells were installed inside the rigid aluminium case and the case was filled with epoxy resin. The cell and battery are shown in Fig. 2 .

Fig. 3 shows the block diagram of the electrical power subsystem for REIMEI satellite [5]. Each voltage of individual battery could be monitored. The range for the monitoring of the output voltage was between 0 and 35 $\mathrm{V}$, and the data was acquired by 8 bit data recorder. Thus, the telemetry data for the battery voltage had the accuracy of $\pm 0.136 \mathrm{~V}$ [5].

The current for the charge and the discharge was also monitored individually for each battery between $-3.0 \mathrm{~A}$
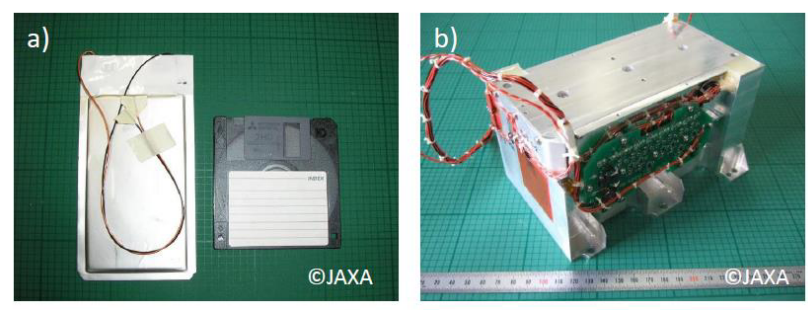

Figure 2. The photographs of the cell (a) and battery (b) for stellite 'REIMEI'.

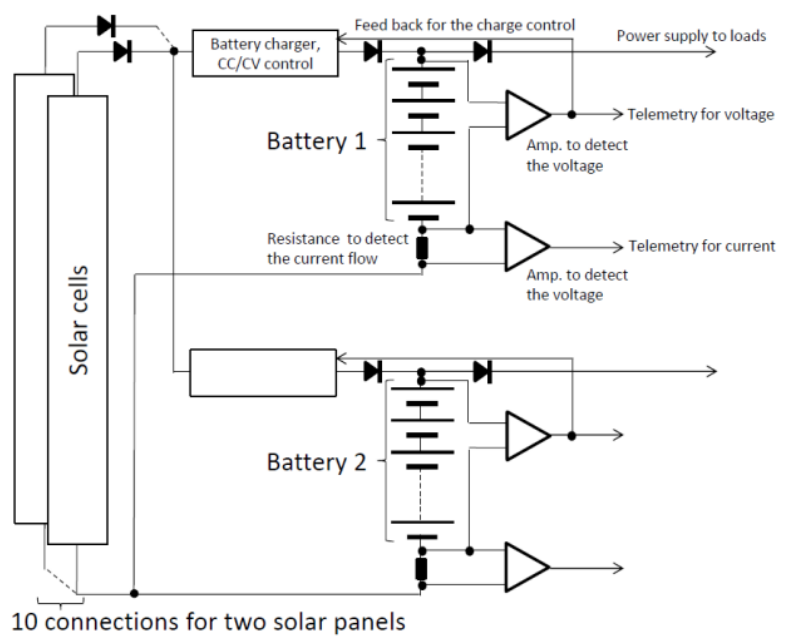

Figure 3. The Block diagram of the electrical power subsystem on-boarded to the satellite 'REIMEI'.

(for the discharge) and +3.0 A (for the charge). The current was also acquired by 8 bit-data-recorder, and had the accuracy of $\pm 23 \mathrm{~mA}$ [5].

\section{ORDINAL OPERATION OF THE BATTERY}

REIMEI was launched in August, 2005. It was injected into the low-earth-polar orbit with the $600 \mathrm{~km}$ altitude. Then, the satellite continuously experiences daytime for 35 minutes and eclipse for 62 minutes during one revolution around the Earth.

For the charge, the 'constant current/constant voltage (CC-CV) control' has been used. The battery was

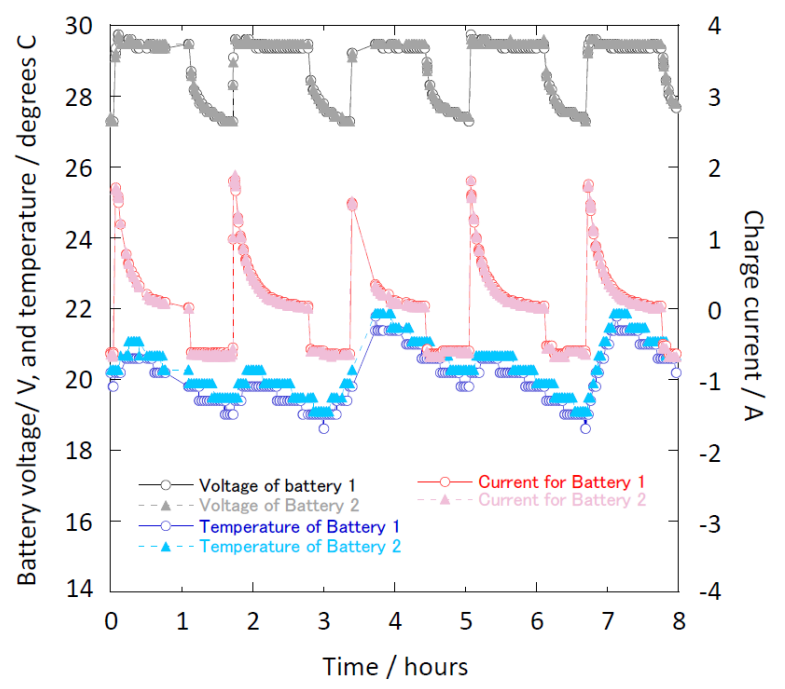

Figure 4. Typical in-flight data of the battery during charge and discharge for 8 hours on September $25^{\text {st }}$, 2012. CC-CV control was applied. For the CV control, V1 level (4.1 V/cell) was used for the charge control. 

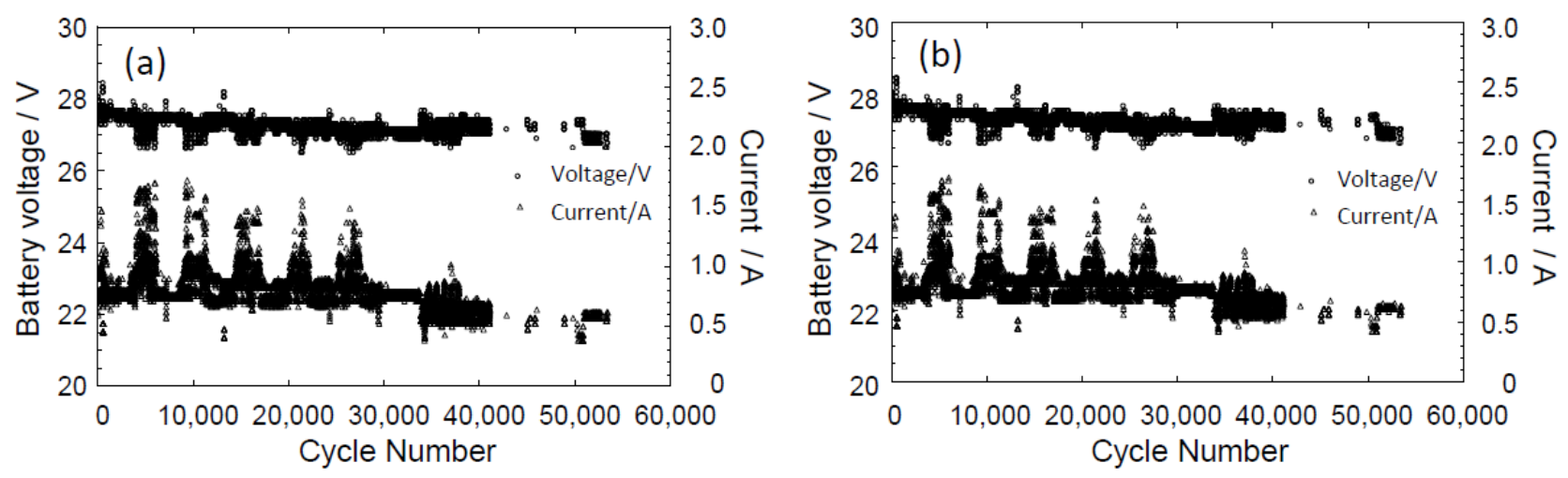

Figure 5. The trend of the voltage and current in the 'end of discharge'.

The responses from the 'Battery 1'(a), and 'Battery 2'(b) are shown.

(Ref. [5] Sone, Y. et al., (2015) Electrochemistry, 84(1), 12-16.)

initially charged using 1.5 A constant current. When the battery voltage reached up to $28.7 \mathrm{~V}(4.1 \mathrm{~V} /$ cell $)$, the power control unit maintained the constant voltage to the end of the daytime. The charge voltage could be occasionally raised up to $29.4 \mathrm{~V}(4.2 \mathrm{~V} /$ cell $)$ to keep the safer operation during the malfunctions.

The discharge current was ca. 1.6 1.8 A for the nominal operation of the satellite. The main scientific mission of the satellite was the observation of aurora around the polar region using three cameras with different filters for the wave length of the light. The most sever operation was the observation of aurora in the end of the night time. Each aurora camera requested 0.5 A extra electricity, and the maximum current requested for the operation of REMEI was $3.3 \mathrm{~A}$ in total. Fig. 4 shows the typical charge and discharge curves during the operation of REIMEI. The dc impedance of the battery was large enough, and the battery voltage soon arrived to the $\mathrm{CV}$ control region when the charge started. The temperature was well controlled between 19 and 22 degrees $\mathrm{C}$ by the heater control.

The trend of the 'end of discharge voltage' of the battery is shown in Fig. 5 [5]. By monitoring the drop of the discharge voltage by the changed of the load and the discharge current, we maintained the end of discharge voltage above the 'under-voltage-control (UVC)' level. We have several blank of data due to the natural disaster like earthquake and typhoon, but the operation was continuously maintained.

Even after the operation for eleven years, the two different batteries have been supplying almost same current individually to the satellite loads in the orbit.

\section{IN-ORBIT IMPEDANCE ANALYSIS}

In 2013, the scientific mission like aurora observation was dismissed. After the termination of the scientific missions, we decided to operate the satellite to confirm the operability of the lithium-ion secondary cells in space.
It is well known that the impedance of the cell is increasing with cycles, and the precise understanding of electrochemistry inside the cell is very important for the prolonged operation of the battery. For that purpose, we tried to understand the internal impedance of the cells and batteries.

Fig. 6 shows the trend of the dc impedance obtained from the REIMEI battery. When the charge of the battery starts, the large increase in voltage is always observed. Furthermore, the large drop of discharge voltage can also be observed, when the discharge of the battery starts. From the change, we calculated the dc impedance of the battery.

The trend shown in Fig. 6 depicted that the calculated dc impedance did not change even after the operation for years. It is well known that the repeated use of the

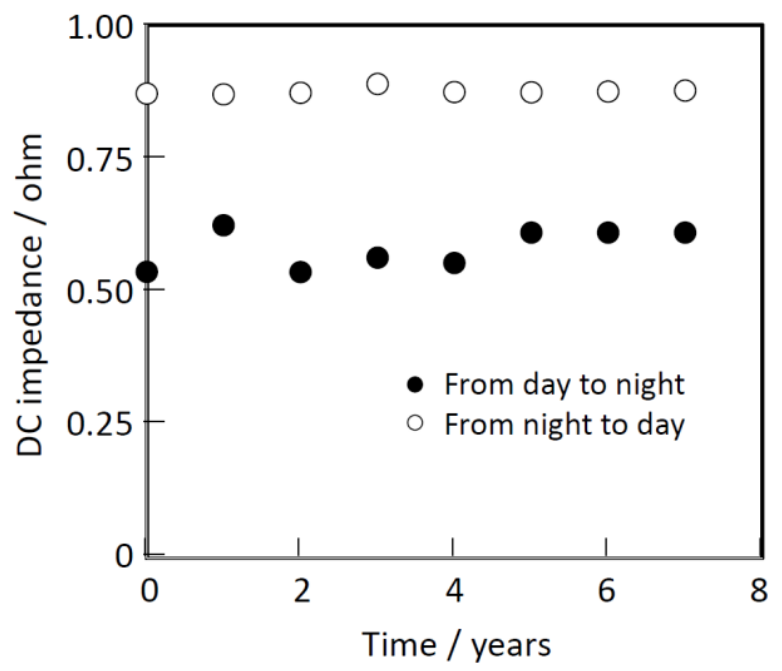

Figure 6. The trend of dc impedance calculated from the REIMEI battery.

The impedance was calculated from the change in voltage and current at the end and beginning of 


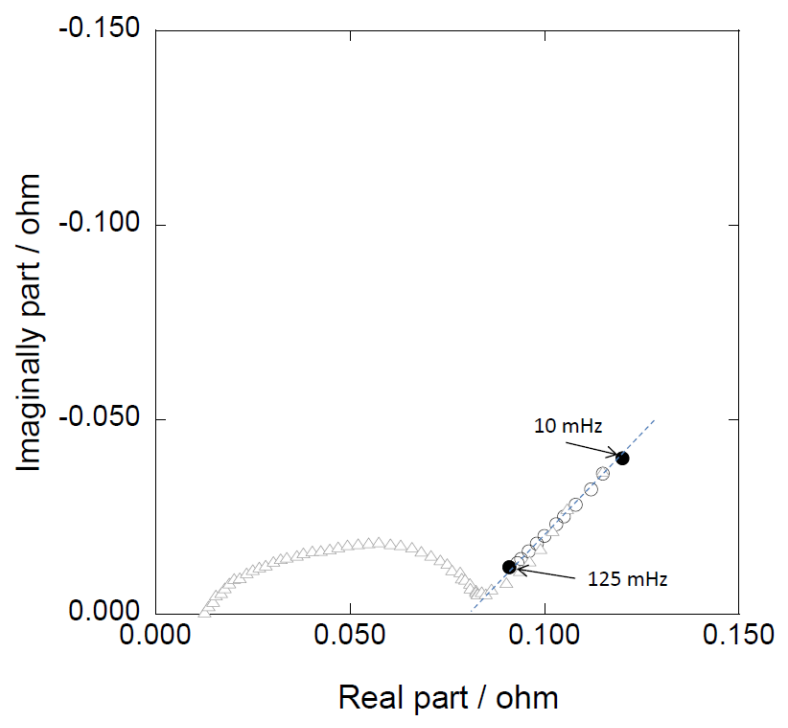

Figure 7. Nyquist plot calculated from the pulse duration to the REIMEI battery.

The result calculated from the in-orbit data (O), and the simulation based the terrestrial experiment $(\triangle)$ are shown.

(Ref. [6] Sone, Y. et al., (2015) 1M06, Proc.83 ${ }^{\text {rd }}$ Meeting of the Electrochem. Soc. of Japan.)

lithium-ion secondary cells for charge and discharge causes the increasing thickness of the SEI, which finally causes the decrease in the discharge voltage and capacity. The results we obtained through the $\mathrm{dc}$ impedance suggested that the information of the $\mathrm{dc}$ impedance did not reflect the internal conditions of the battery/cell. We imagined that the impedance loss by the leads were the major part calculated in this case.

Then, we decided to calculate the ac impedance of the battery/cell through the in-orbit operation. When the pulse duration was induced to the batteries, the drop of discharge voltage could be observed. Based on the change in potential, we used Fourier transformation, and tried to obtain the information about ac impedance.

However, we had a problem. The REIMEI battery uses 7 cells to realize the $28 \mathrm{~V}$-class-bus-voltage. To detect the bus voltage, the range for the output voltage between 0 and $35 \mathrm{~V}$ was divided by 8 bit, thus the accuracy of the voltage is $\pm 0.136 \mathrm{~V}$. Furthermore, the data is acquired every 8 seconds. Thus, the ac impedance with low frequency region could be obtained through the mathematical method.

However, most information about the degradation of the cells is usually obtained as the charge transfer resistance. For the consideration, Nyquist plots are commonly used. Fig. 7 shows the Nyquist plot obtained from the onboarded REIMEI battery. The ac impedance less than $100 \mathrm{mHz}$ were obtained [6].

In Fig. 7, semi circler region is also shown. It was very fortunate that the cells which were obtained at almost the same time as the flight ones were still stored for the

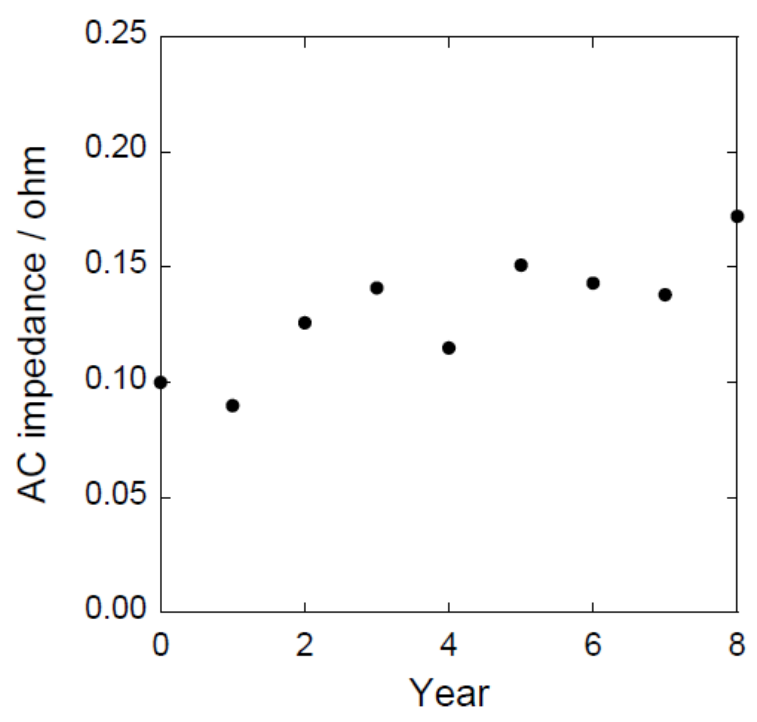

Figure 8. The trend of AC impedance of the lithiumion secondary cell calculated from the pulse duration to the REIMEI battery.

terrestrial measurements. By using the cells, the basic shape of the Nyquist plot of the cell could be obtained. Based on the information, we simulated the Nyquist plot whose lower frequency region could overlap each other. We considered that the diffusion area for the original Nyquist plot was observed by the calculation based on the in-orbit data. We also believed that the sum of the resistances among the solvent and the charge transfer regions could be obtained by the linear extrapolation of the calculated ac impedance.

Today, we are trying to observe the change in ac impedance inside the batteries/cells. Fig. 8 shows the trend of the increase in the ac impedance. Now, the constant increase in impedance is obtained, which reflects the performance of the battery taking place after the long term operation of REIMEI satellite. It is well known that the increase in ac impedance proceeds due to the degradation of capacity and formation of Solid Electrolyte Interface (SEI).

\section{SUMMARY}

The satellite 'REIMEI' was designed using off-the-shelf lithium-ion secondary cells for the main bus battery. The spinel manganese oxide was used for the positive and the graphitized carbon was used for the negative. Since the satellite was injected to the low earth orbit which spends 97 minute for one revolution, the battery must be charge and discharged very rapidly.

Even after the eleven years operation, the REIMEI satellite is still operative. Two batteries are used for the satellite, and the distributed current to each battery was almost equal, which shows that the tow batteries for the satellite still maintain good balance.

Direct current impedance and alternated current impedance was calculated to analyse the condition of 
the batteries. Through the ac impedance, constant increase in impedance was observed, which suggest the ordinal degradation proceeds inside the cell.

\section{ACKNOWLEDGEMENT}

This research is partially supported by 'International Joint Research Program for Innovative Energy Technology' of Ministry of Economy, Trade and Industry (METI).

\section{REFERENCES}

1. Spurrett, R., Thwaite, C., Slimm, M. and Lizius, D. (2002) Lihium-Ion Batteries for Space, Proc. $6^{\text {th }}$ Euro. Space Power Conf., 477-482.

2. Saito, H., Masumoto, Y., Mizuno, T., Miura, A., Hashimoto, M., Ogawa, H., Tachikawa, S., Oshima, T., Choki, A., Fukuda, H., Hirahara, M., Okano, S. (2001). INDEX: Piggy-back Satellite for Aurora Observation and Technology Demonstration", Acta Astronautica, 48, 723-735.

3. Saito, H., Hirahara, M., Mizuno T., Fukuda S., Fukushima, Y., Asamura, K., Nagamatsu, H., Tanaka, K., Sone, Y., Okuizumi, N., Mita, M., Uno, M., Yanagawa, Y., Takahara, T., Kaneda, R., Honma, T., Sakanoi, T., Miura, A., Ikenaga, T., Ogawa, K., Masumoto, Y. (2011). Small Satellite REIMEI for Auroral Observations, Acta Astronautica, 69, 499-513.

4. Uno, M., Ogawa, K., Takeda, Y., Sone, Y., Tanaka, K., Mita, M., Saito, H. (2011). "Development and On-orbit Operation of Lithiumion Pouch Battery for Small Scientific Satellite "REIMEI"”, J. Power Sources, 196, 8755-8763.

5. Sone, Y., Watanabe, H., Tanaka, K., Fukuda, S., Ogawa K., Asamura, K., Yamazaki, A., Nagamatsu, H., Fukushima, Y., and Saito, H. (2015). Long Term Operability of Li-ion Battery under Micro-gravity Condition Demonstrated by the Satellite "REIMEI", Electrochemistry, 84(1), 12-16.

6. Sone, Y., Watanabe, H., Tanaka, K., Fukuda, S., Itagaki, M., Ogawa K., Asamura, K., Yamazaki, A., Nagamatsu, H., Fukushima, Y., and Saito, H. (2015). Analysis of the Battery Condition of REIMEI Satellite after the Long-Term Operation in Space, 1M05, Proceedings of the $83^{\text {rd }}$ Meeting of the Electrochemical Society of Japan, The Electrochemical Society of Japan, Suita, Japan.

7. Bausier, F., Tonicello, F., and Soares, T. (2014). Passivation of Spacecraft Electrical power System at End of Mission, Proceedings of the $10^{\text {th }}$ European Space Power Conference, ESA SP719 (CD-ROM), European Space Agency, Noordwijk, The Netherlands.

8. Alcindor, P., Kimber, R., Remy, S., and Prevot, D. (2014). Passivating Li-ion Batteries in Orbit at the
End of the Spacecraft Life, Proceedings of the $10^{\text {th }}$ European Space Power Conference, ESA SP719 (CD-ROM), European Space Agency, Noordwijk, The Netherlands.

9. Dudley, G. Extension of Lithium Ion Cell model to Include Transient and Low Temperature, Proceedings of the $10^{\text {th }}$ European Space Power Conference, ESA SP-719 (CD-ROM), European Space Agency, Noordwijk, The Netherlands. 